\title{
Erratum to: Heparan sulfate expression is affected by inflammatory stimuli in primary human endothelial cells
}

\author{
Trine M. Reine • Marion Kusche-Gullberg • \\ Almir Feta • Trond Jenssen • Svein O. Kolset \\ Published online: 17 March 2013 \\ (C) Springer Science+Business Media New York 2013
}

\section{Erratum to: Glycoconj J (2012) 29:67-76 DOI 10.1007/s10719-011-9365-y}

The original version of this article unfortunately contained mistakes. The changes are as follows emphasized in bold:

\section{Page 72:}

"Treatment with TNF- $\alpha$ and TGF $\beta$, on the other hand, resulted in a small decrease in the total amount of 6-O-sulfated glucosamine residues whereas IL- $1 \alpha$ treatment had the opposite effect."

\section{Should read:}

"Treatment with TNF- $\alpha$ and $\boldsymbol{I L}-\boldsymbol{I} \boldsymbol{\alpha}$, on the other hand, resulted in a small decrease in the total amount of 6-O-sulfated glucosamine residues whereas $\boldsymbol{T} \boldsymbol{G F} \boldsymbol{\beta}$ treatment had the opposite effect."

Page 73, Table 1:

"TNF $\alpha$ " should read "IL-1 $\alpha$ "

"IL-1 $\alpha$ " should read "TGF $\beta$ "

"TGF $\beta$ " should read "TNF $\alpha$ "

The online version of the original article can be found at http:// dx.doi.org/10.1007/s10719-011-9365-y.

T. M. Reine $\cdot$ S. O. Kolset $(\bowtie)$

Department of Nutrition, Institute of Basic Medical Sciences,

University of Oslo,

Box 1046, Blindern,

0316 Oslo, Norway

e-mail: s.o.kolset@medisin.uio.no

M. Kusche-Gullberg • A. Feta

Department of Biomedicine, University of Bergen,

5020 Bergen, Norway

\section{T. Jenssen}

Kidney Section, Department of Organ Transplantation,

Oslo University Hospital - Rikshospitalet,

0027 Oslo, Norway

\section{T. Jenssen}

Department of Clinical Medicine, University of Tromsø,

9037 Tromsø, Norway
Please find the correct version of Table 1 below

Page 74, second paragraph:

"Finally, compositional analyses of 35S-HS disaccharides generated by low $\mathrm{pH}$ nitrous acid deamination demonstrated reduced total 6-O-sulfation after treatment with TNF- $\alpha$ and TGF- $\beta$ and a small increase with IL- $1 \alpha . ”$

Should read:

"Finally, compositional analyses of 35S-HS disaccharides generated by low $\mathrm{pH}$ nitrous acid deamination demonstrated reduced total 6-O-sulfation after treatment with TNF- $\alpha$ and $\boldsymbol{I L}-\boldsymbol{I} \boldsymbol{\alpha}$ and a small increase with $\boldsymbol{T G F}-\boldsymbol{\beta}$ ”

Page 75, second paragraph:

"Results from the present study show that the 6-O-sulfation is changed when HUVEC were cultured with TNF- $\alpha, I L-1 \alpha$ or IL-1 $\beta$ for only $24 h$."

Should read:

"Results from the present study show that the 6-O-sulfation is changed when HUVEC were cultured with TNF- $\alpha, I L-1 \alpha$ or TGF- $\boldsymbol{\beta}$ for only 24 h."

The correct version of Table 1:

Table $1 \%$ of $\mathrm{O}-^{35} \mathrm{~S}$-sulfated disaccharides after the indicated treatments

\begin{tabular}{lcc}
\hline Treatment & $\begin{array}{l}\text { Total 2-O- }{ }^{35} \text { S containing } \\
\text { disaccharides }\end{array}$ & $\begin{array}{l}\text { Total 6-O- }{ }^{35} \text { S containing } \\
\text { disaccharides }\end{array}$ \\
\hline LG & $92.8 \pm 1.5$ & $32.2 \pm 4.9$ \\
HG & $92.5 \pm 2.0$ & $32.2 \pm 7.7$ \\
IL-1 $\alpha$ & $92.1 \pm 2.0$ & $27.3 \pm 6.2$ \\
TGF $\beta$ & $91.6 \pm 2.1$ & $34.5 \pm 8.0$ \\
TNF $\alpha$ & $93.5 \pm 1.6$ & $28.4 \pm 6.1$ \\
IL-1 $\beta$ & $92.5 \pm 2.5$ & $32.5 \pm 0.5$ \\
\hline
\end{tabular}

